\title{
Depression and Adjustment to Retirement Among Retiree Teachers in Meru County, Kenya
}

\author{
Aileen Gacheri Akwalu Mugambi ${ }^{1} \quad$ Beatrice Mwarania Mburugu $^{2} \quad$ John Kamoyo Mwithalii ${ }^{2}$ \\ 1.Department of Social Sciences, Chuka University \\ 2.Department of Education, Chuka University
}

\begin{abstract}
Retirement is gradually becoming a topic of research in contemporary society. This is because it is one of the challenges associated with aging. Growing old is not easy and involves life changes which demand multiple adjustments requiring stamina, ability and flexibility. Studies have concluded that retirement leads to depression and it was therefore important to establish the between depression and adjustment to retirement. This study established a significant relationship between depression and adjustment to retirement among retiree teachers in Meru County. The target population of study was 1800 respondents comprising retiree teachers, spouses of retirees teachers and close relatives of the retiree teachers. A sample of 318 respondents was selected to participate in the study. Data was collected from retiree teachers and their spouses through questionnaires. Interview schedules were used to collect data from retiree teacher close relative. Quantitative data was analyzed with the help of Statistical Package for Social Science (SPSS) version 23. Descriptive statistics included frequencies, percentages, standard deviation and mean. Inferential statistics used was Wilcoxon signed rank test. Qualitative data collected was analyzed by classifying the responses into meaningful categories thematically. The findings of this study revealed that there is a significant relationship depression and adjustment to retirement. The study recommends that government of Kenya to organize pre-retirement and post-retirement counseling to help teachers to handle challenges that lead to depression in retirement.
\end{abstract}

DOI: $10.7176 /$ RHSS/10-16-02

Publication date: August $31^{\text {st }} 2020$

\section{Introduction}

Retirement is a period of transition during which one leaves a known way of doing and being, often enters unknown territory, and may experience significant feelings of loss and associated grieving that may lead to depression (Malette and Oliver, 2006). Retired individual may also be subjected to aging stigma which may also lead to depression. Retirement is a disengagement process that enables the aging person to be freed of the daily responsibilities of a job and to pursue fewer, more self-selected activities. Through disengagement, society anticipates the loss of older people through death and makes room to bring new cohorts into full participation within the social world. The withdrawal of the older person from various social roles means that employers will lose a critical employee suddenly, and families lose a member with major responsibilities to kin due disengagement from these responsibilities. When one retires from employment, they lose friends and perhaps withdraw from community activities as they age which may led to depression. These facts are applicable to retiree teachers because they are aged.

Retirement stage of life can be a pleasant experience for some, yet traumatic for others (Marshall, 2004). This is due to the fact that it brings with it many challenges in terms of adjustments and changes in lifestyle, selfesteem, friendships, and vocation. To such, the thought of retirement brings anxiety, apprehension and disillusionment. When retirement is drawing near, people ask questions like where one will find purpose, whether people will remember their retiree, What one will be after retirement, what the retiree life will mean, what retiree will do with his/her time, whether they will have saved enough money for their spending, whether they will have their spending and freedom drastically curtailed, (Osumah, 2015). These questions of not properly handled can lead to depression.

Retirement leads to anxiety that involves fears and worries about the future of the individual as a result of the cessation of active working life. It involves fear that usually results from change, is inevitable but most people tend to resist change because it is not always convenient (Bryant et al., 2008; Rodda et al., 2008). As a result of this denial of the changes, others have experienced negative retirement outcomes such as increased drinking, smoking, and the risk of depression (Van \& Henkens, 2008; Szinovacz \& Davey, 2004).

According to the World Health Organization, depression as a pathological state that is associated with feelings of loss or guilt and characterized due to sadness, lowering of self-esteem, disturbed sleep or appetite, feelings of tiredness, and poor concentration. Clinical depression can be diagnosed by the duration and severity of sadness. Normal sadness or Short-lived feelings of depression which do not result in impaired functioning are not clinical depression. Clinical depression is diagnosed when the signs of depression are present in an individual for at least a period of two weeks. Kim and Moen (2002) said that symptoms of depression include but no limited to losing interest in the things you used to enjoy doing, feeling irritable or restless, having problems 
getting to sleep or waking up in the morning, having changes in appetite or weight, having problems with thinking, making decisions or remembering things, feeling tired all the time, feeling worthless or excessively guilty, feeling helpless and thinking about death or suicide.

Studies have identified work status as an important factor associated with depression among older adults (Rodda et al., 2011). The financial stress from losing or resigning a job is one of the most common stressful events for older adults, especially when there is no social support to compensate for this financial change. However, financial stress is not the only explanation for the relationship between work status and depression in older adults. In fact, other explanatory pathways have been suggested for the effect of retirement, or the job loss (compared to remain working), on the health of older adults, such as: changes in social networks, social isolation, decreased self-esteem, and a poor perception of usefulness and empowerment. According to Jahoda's proposal, the poor perception of usefulness, along with time structuring and fostering activity, can be regarded as latent consequences of loss of work, which links work status and individual's well-being (Jahoda, 2009).

Studies have reported positive events of retirement which include psychological benefits such as life satisfaction, improvement in mental health, increase in morale for men, and reduction in mental fatigue as well as depressive symptoms (Kim \& Moen, 2002). Retirees who worked in a poor environment and were in poor health experienced a steeper increase in health after retirement. However, not all retirees seem to enjoy the physical and psychological benefits of retirement. Lee and Smith (2009) states that results from a study on work, retirement and depression suggested that retirement by itself may not create depression. Although retirees are more depressed than paid workers it seems that causes that induce retirement such as poor healthcare giving responsibilities and the inability to find a job are also associated with depression.

Different Scientific disciplines such as economics, sociology and psychology have tried to explain retirement. Psychological approach postulates that people who retire are vulnerable to feeling of loss which can lead to psychological distress. Empirical evidence with respect to psychological consequences of retirement is inconsistent. Some researchers have found significant negative relationship between retirement and life satisfaction or morale and positive association with psychological distress (Kim \&Moen, 2012). Other researchers found no negative psychological effects such as psychological distress associated with retirement and some have reported mixed findings (Ross \& Drentea, 2008).

Retirement is a major crisis especially in sub-Saharan Africa because there is an absence of pre-retirement counseling given by employers to employees, which would generate changes that normally facilitate the transition from work to retirement (Ogunbameru, 2004). A close observation of many retirees in the Ghanaian society and problems they range from sudden loss of life, delayed payment of benefits, loss of usual monthly salary, anxiety about a residential home, lack of occupation, dwindling status, decreased strength and deteriorated health condition, physical disabilities and aging all which might lead to depression, According to Ogunbamery (2004), retirement could be more than withdrawal rather it is a major crisis especially in Nigeria because there is an absence of pre-retirement counseling given by employers to employees, which would generate changes that normally facilitate the transition from work to retirement may be perceived as resulting into loss of status especially, if the retiree is a bread winner.

Several studies have been done in Kenya with regard to teacher retirement. Nyaboke (2016) looked at the challenges affecting livelihood of teachers after retirement in Kisii Central Sub County, Kisii County. Mboga (2014) looked at the social and cultural dynamics of life after retirement from public service in Kenya with focus on the retirees from Kenyatta National Hospital. Thuku (2013) did a study on the influence of retirement preparation on happiness in retirement focusing on retirees in Nyeri County. Githui (2012) studied the perception of retirement by teachers in public secondary schools in Nairobi. Orina (2014) did a study on the assessment of factors leading to early retirement of public secondary school teachers in Kajiado County. While these studies are beneficial to the researcher, none was done on the relationship between depression and adjustment to retirement among retired teachers in Meru County.

\section{Statement of the problem}

Studies have reported an association of retirement with enhanced physical health. Other studies have reported negative effects of retirement on health such as depression. . Reasons for depression of a retired person are loss of job, changing home dynamics for one or both spouses may have worked away from home for sometimes and have to adjust to spending most of their times at home.. There may be a need for changing roles in the family and a greater need for joint decision making. This may lead to conflicts as each spouse adjusts to the new situation causing depression among the retirees. . Depression may create challenges of adjustment to retirement among retirees. Various studies have established association between depression and adjustment to retirement. However, little is known on the association between depression and adjustment to retirement among retired teachers in Meru County hence this study set out to fill the gap. 


\section{Objective of the Study}

The study set out to establish the relationship between depression and adjustment to retirement among retiree teachers in Meru County of Kenya

\section{Hypothesis}

$\mathrm{H}_{01} \quad$ There is no statistically significant relationship between depression and adjustment to retirement among retiree teachers in Meru County, Kenya.

\section{Research Design}

This study adopted a descriptive survey research design.

\section{Location of the Study}

The study was conducted in Meru County of Kenya. .

\section{Population of the Study}

The target population was 1800 persons comprising of 600 retiree teachers, 600 spouses to retiree teachers and 600 close relatives of retiree teachers.

\section{Sampling Procedures and Sample Size}

The study sampled 318 respondents who were proportionately selected. The sample was distributed as shown it Table 1:

Table 1: Sample Size

\begin{tabular}{|c|c|c|c|}
\hline Group & Population & Sample Size & Sampling Procedure \\
\hline Retiree Teacher & 600 & 106 & Snowballing \\
\hline Spouses of Retiree Teachers & 600 & 106 & Purposive \\
\hline Retiree Teachers 'close relatives & 600 & 106 & Simple Random \\
\hline Total & 1800 & 318 & \\
\hline
\end{tabular}

Research Instruments

Questionnaires and interview schedules were used to collect data from the respondents.

\section{Data Analysis}

Statistical Package for Social Science version 23 was used to analyze data.

\section{Ethical Considerations}

The researcher was guided by American Psychological Association (APA) ethical principles of psychologists and code of conduct (APA, 2002).

\section{Demographic Characteristics for Retirees}

The demographic characteristics for the retiree teacher's that were considered in this study were; the spouses' gender, marital status and religion. Among the respondents, 50\% were male and 50\% were female. Most of the retired teachers were aged $61-65$ years). The recommended age of retirement for teachers in Kenya is 60 years. Over $50 \%$ of the retired teachers in this study were 60 years and above. However, there were still retired teachers who aged less than 60 years. Analysis of the retired teachers by religion and marital status showed that the highest percentages of the retired teachers in Meru count were Christians and they were married |. The retired teachers who had retired as primary school teachers were $40.57 \%$ while $33.02 \%$ were secondary school teachers

\section{Demographic Characteristics of the Retiree Teachers Spouses}

The demographic characteristics for the retiree teacher's spouses that were considered in this study were; the spouses' gender, marital status and religion. $53.8 \%$ of the retirees' spouses who were respondents in this study female and $46.2 \%$ of the spouses were males. Analysis of the ages of the spouses to the retiree's s teachers indicated that $13.21 \%$ were below 50 years, $19.81 \%$ were between $51-55$ years while $33.96 \%$ were between 56 60 years. The results showed that majority of the spouses had attained the retirement age just as the retirees. Analysis of the retiree teacher's spouses who based on their religion showed that $8.49 \%$ of the spouses did not belong to any religion. Majority of the spouses (53.77\%) were Christians with the next highest percentage being the Muslims. The Hindus, African traditional believers and other religions accounted for about $10 \%$ of the respondents in this study who were spouses to the retirees. 


\section{Demographic Characteristics of the Retiree Teacher's close Relatives}

The demographic characteristics of the retiree's close relatives that were considered to be in this study were the relative's gender, age and duration of the relationship between the retirees and the relative. Results indicate that $51.9 \%$ of relatives who were respondents in this study were males while $48.1 \%$ of the relatives were females. The average age of the relatives to retiree teachers was 45.46 years.

\section{Depression and Adjustment to Retirement}

The relationship between depression and adjustment to retirement was analyzed using both the descriptive statistics and the inferential statistics. The descriptive statistics analysis results were obtained by summarizing the responses of the retirees, the retirees' spouses and relatives: Table 2

Table 2: Responses on Retirees on Depression

\begin{tabular}{|c|c|c|c|c|c|c|c|c|c|c|}
\hline Variable & 5 & 4 & 3 & 2 & 1 & $\mathrm{f}$ & Med 1 & avg & sd & Mode \\
\hline Retiring makes me bitter & 44 & 14 & 11 & 18 & 19 & 106 & 4 & 3.43 & 1.59 & 5 \\
\hline I feel miserable and sad because of retirement & 30 & 27 & 8 & 12 & 29 & 106 & 4 & 3.16 & 1.61 & 5 \\
\hline I have thought of committing suicide severally since I retired & 30 & 13 & 9 & 15 & 39 & 106 & 2 & 2.81 & 1.69 & 1 \\
\hline I sweat most of the times since I don't like retirement life & 36 & 22 & 11 & 13 & 24 & 106 & 4 & 3.31 & 1.59 & 5 \\
\hline I cry over little things since retirement & 34 & 23 & 12 & 14 & 23 & 106 & 4 & 3.29 & 1.56 & 5 \\
\hline I do not like life in retirement & 39 & 22 & 14 & 7 & 24 & 106 & 4 & 3.42 & 1.58 & 5 \\
\hline There is no freedom in life after retirement & 40 & 27 & 8 & 10 & 21 & 106 & 4 & 3.52 & 1.55 & 5 \\
\hline I have a lot of fear since retirement & 39 & 23 & 10 & 9 & 25 & 106 & 4 & 3.4 & 1.61 & 5 \\
\hline There is no hope for the future in retirement & 38 & 27 & 10 & 7 & 24 & 106 & 4 & 3.45 & 1.57 & 5 \\
\hline I am restless and can't keep still since retirement & 43 & 27 & 5 & 8 & 23 & 106 & 4 & 3.56 & 1.59 & 5 \\
\hline I sleep most of the times since retirement & 43 & 24 & 13 & 6 & 20 & 106 & 4 & 3.6 & 1.52 & 5 \\
\hline I am less interested in other people or things ever since retirement & 48 & 25 & 7 & 4 & 22 & 106 & 4 & 3.69 & 1.57 & 5 \\
\hline
\end{tabular}

Results in Table 2 shows that retired teachers tended to agree that retiring made them bitter, they felt miserable and sad because of retirement, they sweated most of the times since they did not like retirement life, cried over little things since retirement, they did not like life in retirement, there was no freedom in life after retirement, had a lot of fear since retirement, there was no hope for the future in retirement, felt restless and couldn't keep still since retirement, slept most of the times since retirement and they were less interested in other people or things since they retired (Table 2). On a five point Likert scale these statement had a median of 4. However, these retirees disagreed to the statement that they had thought of committing suicide severally since they retired. The relationship between depression and adjustment to retirement was also analyzed based on the responses from the retirees' spouses: Table 3.

Table 3: Responses on Retirees' Spouses on Depression

\begin{tabular}{|c|c|c|c|c|c|c|c|c|c|c|}
\hline Variable & 5 & 4 & 3 & 2 & 1 & $\mathrm{f}$ & med & Avg & sd & Mode \\
\hline Retiring makes my spouse bitter & 22 & 50 & 4 & 6 & 24 & 106 & 4 & 3.38 & 1.46 & 4 \\
\hline My spouse feels miserable and sad because of retirement & 27 & 24 & 25 & 20 & 10 & 106 & 3 & 3.36 & 1.3 & 5 \\
\hline My spouse has thought of committing suicide severally since retirement & 6 & 16 & 19 & 30 & 35 & 106 & 2 & 2.32 & 1.24 & 1 \\
\hline My spouse sweats most of the times since they don't like retirement life & 26 & 45 & 4 & 6 & 25 & 106 & 4 & 3.39 & 1.51 & 4 \\
\hline My spouse cries over little things since retirement & 24 & 28 & 24 & 24 & 6 & 106 & 3 & 3.38 & 1.22 & 4 \\
\hline My spouse does not like life after retirement & 31 & 38 & 9 & 3 & 25 & 106 & 4 & 3.44 & 1.52 & 4 \\
\hline My spouse has no freedom in life since retirement & 21 & 47 & 6 & 2 & 30 & 106 & 4 & 3.25 & 1.53 & 4 \\
\hline My spouse has a lot of fear since retirement & 23 & 44 & 5 & 3 & 31 & 106 & 4 & 3.24 & 1.56 & 4 \\
\hline There is no hope for the future in retirement & 24 & 23 & 5 & 24 & 30 & 106 & 2 & 2.88 & 1.58 & 1 \\
\hline My spouse is restless and can keep still since retirement & 20 & 26 & 7 & 3 & 50 & 106 & 2.5 & 2.65 & 1.68 & 1 \\
\hline My spouse sleeps most of the times since retirement & 26 & 23 & 4 & 25 & 28 & 106 & 2.5 & 2.94 & 1.58 & 1 \\
\hline My spouse is less interested in other people or things ever since retirement & 23 & 20 & 11 & 21 & 31 & 106 & 3 & 2.84 & 1.56 & 1 \\
\hline
\end{tabular}

Likert scale score strongly agree $=5$ agree $=4$, not sure $=3$, disagree $=2$, strongly disagree $=1$

Table 3 shows the descriptive statistics of the responses of the retirees' spouses on the relationship between depression and retirement. The spouses to the retired teachers tended to agree to the statements that Retiring made their spouses bitter, their spouses sweat most of the times since they didn't like retirement life, their spouse did not like life after retirement; their spouses had no freedom in life since retirement and had a lot of fear since retirement. They disagreed with the statement that their spouses had thought of committing suicide severally since retirement and that there was no hope for the future in retirement. In addition, they were not sure if their spouses felt miserable and sad because of retirement, if their spouses cried over little things since retirement, if their spouse were restless and couldn't keep still since retirement and if their spouses were less interested in other people or things ever since retirement

The descriptive statistics analysis on the relationship between depression and retirement was also extended to the responses of the retirees' close relatives. Results revealed that $(42.45 \%)$ of retiree teachers close relatives observed mood swing among the retired teachers while $30.19 \%$ of the close relatives observed a dislike in lifestyle among the retired teachers. The percentage of the close relatives that reported observing bitterness among the retired teachers was $27.36 \%$.

\section{Relationship between Depression and Adjustment to Retirement}

The relationship between depression and retirement was also analyzed by use of inferential statistics. This was 
done by testing the hypothesis that there is no statistically significant relationship between depression and adjustment to retirement among retiree teachers. This hypothesis was tested using one-sample Wilcoxon signed rank test. The one-sample Wilcoxon signed rank test is a non-parametric alternative to one-sample t-test when the data cannot be assumed to be normally distributed (Verzani, 2014). It is used to determine whether the median of the sample is equal to a known standard value (i.e. theoretical value). The variables used were the10item Kessler psychological distress scale (K10) scores obtained from the retirees' data (Bougieet al., 2016). The Kessler psychological distress scale $(\mathrm{K} 10)$ is designed to measure anxiety and depression through a 10-item questionnaire. Each question pertains to an emotional state and each has a five-level response scale. The higher the score, the greater the psychological distress due to depression or anxiety. A score of less than 15 shows no distress or anxiety. A score of 16-30 indicates moderate distress and a score of over 30 means high distress (Blanc et al., 2014). The K10 scores obtained using an histogram.

Result showed that the histogram of the scores was skewed to the right which meant that the scores were not normally distributed. This justified using of the wilxocon signed ranked test to analyze the data. The hypothesis tested using the Wilcoxon signed ranked test on the K10 scores could be stated as follows;

$H_{0}: M=30$ Retirees are not under high psychological distress

$H_{1}: M>30$ Retirees are under high psychological distress

Based on the results of Wilcoxon signed ranked test; the null hypothesis was rejected at $\alpha=0.05$ since the probability value (1.17E-09) was less than the level of significance. It can thus be concluded that there was a statistical significant relationship between depression and adjustment to retirement among retiree teachers in Meru County Kenya.

\section{Discussion}

From the above descriptive and inferential results, it is evident that retirement causes depression. The descriptive analysis results showed that some of symptoms of depression are, feeling sad, depressed or just empty, losing interest in things you used to enjoy doing, feeling irritable or restless, having problems getting to sleep or waking up in the morning, having changes in appetite or weight, having problems with thinking, making decisions or remembering things, Feeling tired all the time, feeling worthless or excessively guilty, feeling helpless or hopeless and thinking about death or suicide.

There are possible reasons for depression after retirement. To begin with, a person's sense of self is tied up very strongly in what he or she does for a living; and, with retirement, a sense of loss can occur, leaving a person struggling to understand who they are and what their value is. Second, after somebody retires, the dynamics at home will be changing. Where one or both spouses may have worked out of the home and been away a significant portion of the day, now both spouses may be spending more time at home together. Roles may be changing and a greater need for joint decision-making may be occurring. Until a new equilibrium is attained, there may be conflicts as each spouse adjusts to the new situation. Further, retirement may be seen as a reminder of the fact that the person is aging, with fears about death, sickness, and disability arising. These findings are similar to the ones by Kim and Moen (2002).

Similar results to the ones obtained in this study are the ones by Osborne (2012) who reports that some retirees experience depression or the feeling of void. Others can feel lonely if their partner is younger and still working. A person who is experiencing depression after a loss of job may find a moral conflict is present in some area of life. Other similar results are from a study on work, retirement, and depression suggested that retirement by itself may not create depression (Powers, 2005). Although retirees are more depressed than paid workers, it seems that causes that induce retirement, such as poor health, care-giving responsibilities, and the inability to find a job are also associated with depression. Similar research findings indicate that up to $25 \%$ of people find the transition to retirement is very stressful and the experience a marked reduction in well-being (Bosse \& Kressin, 1996). Research findings also in agreement with the ones in this study have shown that some of the factors that could contribute to such stress are economic conditions, voluntariness of retirement, and national policies on retirement (Agnewm et al., 2012). Insufficient planning has also been identified as a major source of stress after retirement (Agnewmet al,2012)

One of the expectations after retirement is that people think they're going to walk out the door and never look back and spend their days relaxing and traveling with their spouse, but then they get home and they find they can't actually stand the person they have been married to for the last 30 years. This agrees with the finding by Lee \& Smith(2009). Studies have shown that women get stressed out and depressed when their husbands quit work (Melchior et al., 2007). This is because, both had been going in different directions for so long, and all of a sudden they start staring each other in the face. Sometimes the couples realize that they don't really know one another, or that their personalities and interests are completely different.

In agreement with the findings of this study is a study that has stated that after retirement people could have too much time on their hands and they don't know what they want to do (Rogers et al., 2014). Another similar 
study that concurs with this study results indicated that a lot of the relationship troubles seen among retirees comes from either the husband or wife not knowing what they want (Gottmanet al., 2015). The retirees became unhappy, and that unhappiness bleeds out into all areas of their life. Some retirees might also feel that they don't have quite as much money as they thought they would. Under assumption that their health is good, they have probably got a lot of retirement aspirations - things they want to do or places they want to go. Unfortunately, they might not have enough money to do them. When retirement is "less fabulous" than expected, this can be a very unpleasant wake-up call (Merton, 2014). Men mostly get their identities wrapped up in what they do for a living, and once that's gone and there's not something else there to fill the space, that's when the depression and dissatisfaction kicks in (Merton, 2014).

\section{Conclusion}

Based on the study findings the conclusions were made there exists a significant relationship between depression and adjustment to retirement among retiree teachers in Meru County. This was achieved by using the Wilcoxon signed ranked test which led to the rejection of the null hypothesis and a conclusion that retirement causes depression.

\section{Recommendations}

The study recommend that the government of Kenya to introduce pre-retirement and post retirement counseling programmes to prepare retiree teachers to handle psychosocial issues that lead to depression in retirement. .

\section{References}

American Psychological Association. (2002). Ethical principles of psychologists and code of conduct. American Psychologist, 57(12).

Bryant, C., Jackson, H., \& Ames, D. (2008).The prevalence of Anxiety in older adults: Methodological issues and a Review of the Literature. Journal of Affective Disorders; 109, 233-250.

Kim, J.E., \& Moen, P. (2002). Retirement transitions, Gender, and Psychological well-being: A life-course Ecological Model. Journal of Gerontology: Psychological Sciences, 57B (3), 212-222.

Malette, J., \&Oliver L. (2006).Retirement and Existential Meaning in the Older Adult: A Qualitative Study Using Life Review, Counselling, Psychotherapy, and Health, 2(1), 30-49, April 2006.

Marshall, G.L. (2004). The Golden years African American Women and Retirement.Retrieved 09/12/2008 from the World Wide Web http://www.rcgd.isr.umich. edclu/prba/pespectivesummary2004/mcshall.pdf.

Nyaboke, G. (2016). Challenges Affecting the Livelihood of Teachers after Retirement in Kenya: A Case Study of Kisii Central Sub County in Kisii County of Kenya. Master of Arts Project.UniversityofNairobi. Kenya. Nairobi.

Ogunbameru, O. (2004).Attitudes towards Retirement and Pre-retirement Education among Nigerian Bank Workers in Educational Gerontology 30 (5) 391-401.

Rodda, J., Boyce, N., \& Walker, Z. (2008).The Old Age Psychiatry Handbook: A Practical Guide.Chichester, West Sussex, UK: John Wiley \& Sons.

Ross,D.G., \& Wills, L. (2009).Measuring Financial Preparation for Retirement: a New Scale using Australian Evidence. Financial Services Review.18: 381-99

Thuku, P.W. (2013). Influence of Retirement Preparation on Happiness in Retirement: a case of Nyeri County, Kenya. International Journal of Education and Research Vol. 1 No. 3.pp 1-20.

Van Solinge, H.,\& Henkens, K. (2008). Adjustment to and Satisfaction with Retirement: two of a kind? Psychology Aging. 23 (2), 422-34.

Szinovacz, M.E. \& Davey, A. (2004). Retirement Transition and Spouse Disability: Effects on Depressive Symptoms. Journal of Gerontology.59B (6).S333-S342 